\title{
Dental caries and oral health-related quality of life of 3-year-olds living in Lima, Peru
}

\author{
Eraldo Pesaressi $^{1}$ (i) | Rita S. Villena ${ }^{1}$ | Jo E. Frencken ${ }^{2}$
}

${ }^{1}$ Department of Paediatric Dentistry, Dental School, San Martin de Porres University, Lima, Peru

${ }^{2}$ Department of Oral Function and Prosthetic Dentistry, College of Oral Sciences, Radboud University Medical Centre, Nijmegen, The Netherlands

\section{Correspondence}

Jo E. Frencken, Department of Oral Function and Prosthetic Dentistry, College of Oral Sciences, Radboud University Medical Centre, P.O. Box 9101, $6500 \mathrm{HB}$ Nijmegen, The Netherlands.

Email: Jo.Frencken@ radboudumc.nl

Funding information

World Dental Federation (FDI)

\begin{abstract}
Background: Untreated dental caries negatively impacts children and their families; the implication of which is best measured through assessing quality of life. Information related to Oral Health-Related Quality of Life (OHRQoL) in Peruvian pre-school children is scarce.

Aim: To investigate the relationship between dental caries and the OHRQoL of 3year-old children.

Design: Randomly selected government pre-schools $(n=17)$, situated in three low socio-economic status districts in Lima, participated. The OHRQoL data were obtained using the Peruvian (P) ECOHIS questionnaire. Clinical examinations using the Caries Assessment Spectrum and Treatment (CAST) instrument were performed on 308 children. From which, 213 parents returned the P-ECOHIS form. ANOVA, Tamhane, and Tukey methods were used to analyse the data.

Results: The mean age of the children was 3.04 years. The two highest mean PECOHIS scores in the child section were 'child symptoms' and 'child psychology' while 'parent distress' scored highest in the parent section. The prevalence of dental caries was $64.3 \%$ (CAST scores 4-7). Including CASTcode 3 (enamel carious lesion), the dental caries prevalence was $93.4 \%$. The mean P-ECOHIS scores for 'child symptoms', 'child functions', 'child impact', 'parent distress', and 'the sample' were statistically significantly higher for children with MaxCASTcodes 5 and 6 (dentine and pulpally involved cavities, respectively) than for those with MaxCASTcode 3.
\end{abstract}

Conclusion: The presence of cavitated teeth with and without pulpal involvement impacts negatively on the OHRQoL of 3-year-old children.

\section{K E Y W O R D S}

caries assessment spectrum and treatment, dental caries, early childhood oral health impact scale, oral health-related quality of life, paediatric dentistry, primary dentition

\section{1 | INTRODUCTION}

Historically, oral health has been assessed through clinical and objective methods, which do not measure the full impact of disease on the daily living of the individual. ${ }^{1}$ An Early Childhood Caries (ECC) percentage as high as 62.3 has been reported in Peruvian children under 6 years of age. ${ }^{2}$ Untreated,
ECC can trigger a number of negative consequences, including pain, difficulty in chewing, reduced appetite, weight loss, sleep problems, behavioural alterations, low academic performance, and need for hospitalisation. It can also contribute to increased health cost. ${ }^{3,4}$

The concept 'quality of life' is considered a valid parameter for patient assessment in virtually every area of 
healthcare, including oral health. The OHRQoL in young children was unknown for many years because oral health is strongly age-dependent and obtaining subjective perceptions from pre-school children presented a challenge. ${ }^{5}$ However, this picture changed more than a decade ago through the development of different child-related questionnaires. These are as follows: the CPQ - Child Perception Questionnaire ${ }^{6}$; COHIP - Child Oral Health Impact Profile ${ }^{7}$; Child OIDP Oral Impact Dental Profile ${ }^{8}$ and ECOHIS - Early Childhood Oral Health Impact Scale. ${ }^{9}$

The ECOHIS has been developed and tested to assess specifically the impact of dental caries on pre-school children (aged 2 to 5 years) and their families, from the perspective of their parents. ${ }^{9}$ The perception of health and disease in children fluctuates depending on the cognitive capacity of the child according to their emotional, social and language development. ${ }^{10}$ In children under 6 years of age, it is necessary to obtain information from their parents or caretakers ${ }^{11}$ because these children are incapable of recalling day-to-day events after more than 24 hours. ${ }^{12}$ ECOHIS is considered a practical tool for epidemiological surveys and has been validated for Spanish ${ }^{13}$ and culturally adapted for Peruvian populations. $^{14}$

Studies relating OHRQoL to ECC showed ECC children to have pain, difficulty with eating certain foods and difficulty with drinking hot beverages. ${ }^{15-17}$ However, caries assessment instruments such as those of the World Health Organization $(\mathrm{WHO})^{18}$ and the International Caries Detection and Assessment System (ICDAS) ${ }^{19}$ are not capable of revealing the more severe consequences of dental caries such as lesions with pulp involvement, abscesses, or fistulae. For this reason, the Caries Assessment Spectrum and Treatment (CAST) was developed. The CAST instrument uses the epidemiological concept of health and disease and considers treated surfaces with sealants and restorations as being healthy. Its codes depict, in hierarchical order, the increase in caries severity from carious lesions in enamel, through carious lesions in dentine and into the pulp, teeth with an abscess or fistula, and teeth missing owing to dental caries. ${ }^{20}$ Having a spectrum of carious lesion severity in a single instrument is convenient for the investigation of the relationship between OHRQoL and dental caries.

Not many studies have assessed the caries situation of pre-school children in Peru and limited information is available on the disease consequences on the quality of life of these children. ${ }^{14,21,22}$ Moreover, the aforementioned studies have reported solely the presence of cavitation as signs of the disease (dmft). A broader spectrum of reporting dental caries (CAST) might give better understandings of the patterns of dental caries and its effects on the OHRQoL. The aim of the present study was to investigate the impact of dental caries on the OHRQoL of 3-year-old children in Lima, Peru.

\section{Why this paper is important for paediatric dentists}

- This paper may raise awareness for (paediatric) dentists and health professionals of the need to engage with parents from the time the child is born. For many children, the age of 3 may already be too late for maintaining a healthy dentition.

\section{2 | MATERIALS AND METHODS}

\section{1 $\quad$ Study design and sampling}

The present study reports on a reference survey for determining the OHRQoL of pre-school children in Lima, Peru. It is part of a longitudinal intervention trial that will investigate the impact of health centre medical nurses on the reduction of dental caries in children attending motherand-child health $(\mathrm{MCH})$ clinics. The intervention period lasts 3 years, and the methodology has been described on a previous publication. ${ }^{23}$

The sampling unit for the RCT was the healthcare centre. The inclusion criterion was a well-functioning mother-andchild health clinic in the centre situated within a district under the jurisdiction of the Ministry of Health and with a low socio-economic status (SES). The SES selection was guided by economic indicators used by the National Institute of Statistics and Informatics. ${ }^{24}$ On the basis of similar economic indicator outcomes, 3 districts were randomly selected from a total of 10 eligible districts within the Lima Metropolitan area. These districts were situated geographically far apart from each other and were randomly allocated to the three study arms using the software program EASYRA1 (Easy Randomizer, version 4.1).

A total of 45 government pre-schools situated within the geographical vicinity (approx. $2 \mathrm{~km}^{2}$ ) of the three health centres were invited to participate. Ultimately, 17 agreed to be enrolled, seven from the AG, 5 from the PG, and 5 from the CG arms. Children from these pre-schools were listed as being eligible for participation in the study if they were 3 years old, had attended a mother-and-child health centre that complied with the Ministry of Health recommendations (visit for vaccinations from first week of life up to 36 months for reinforcements), and their parents had signed the informed consent form.

\section{2 $\mid$ Oral examinations}

The children's caries status was assessed according to the CAST instrument (Table 1) by two experienced paediatric dentists in the pre-school settings. Prior to the examination, the examiners were trained and calibrated in using the CAST 
T A B L E 1 Codes and descriptions of the hierarchically ordered CAST epidemiological instrument, including disease status

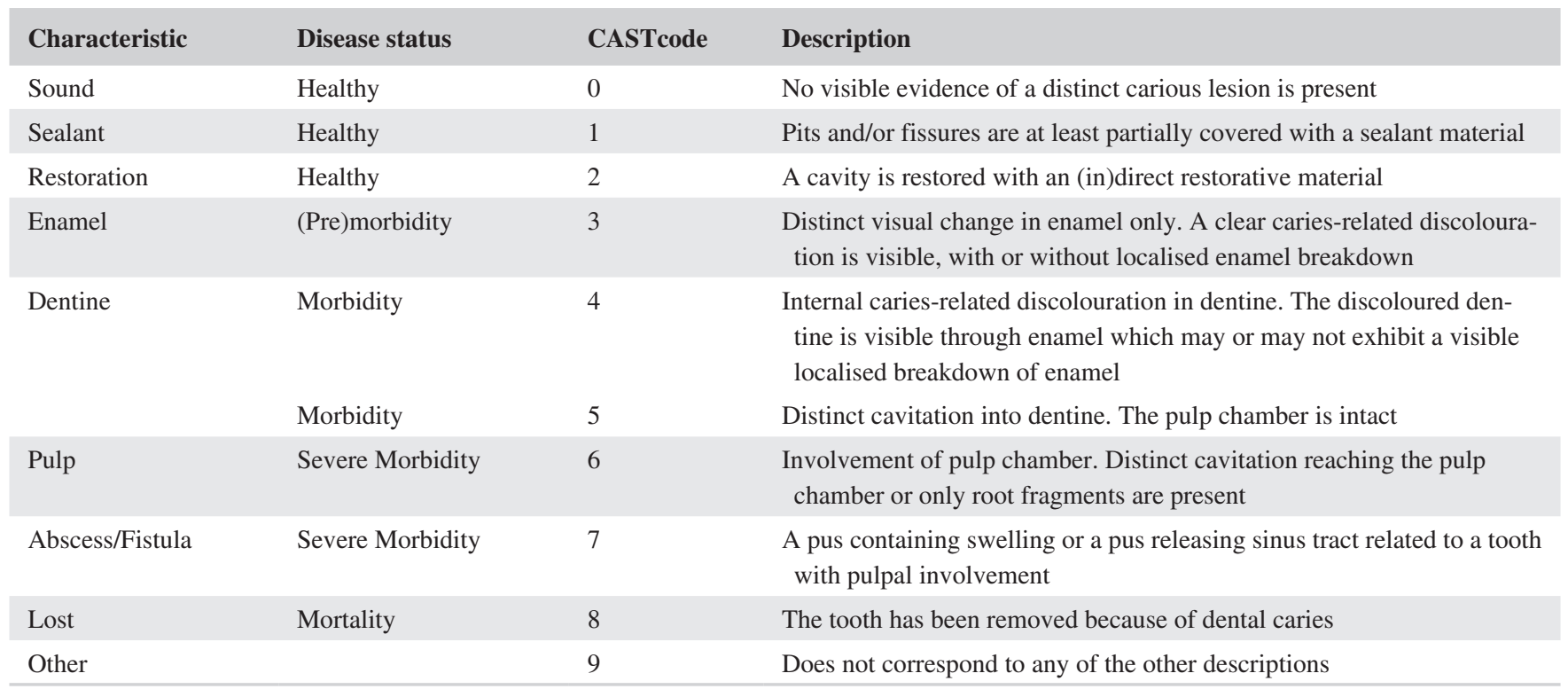

instrument under the guidance of a senior epidemiologist (JEF). During the calibration exercise, inter- and intra-examiner kappa coefficient values ranged from 0.74 to $0.81 .^{25}$

The oral examinations were performed in the pre-school facilities. Prior to examination, patients' teeth were cleaned with a toothbrush, toothpaste, and floss (when needed) by one of the researchers (EP). The child lays on a cushioned table with plastic cover, and the examinations were performed using dental mirrors, probes, and a battery-powered headlight (Energizer 3 LED headlight, Energizer Holdings Inc USA). All surfaces of all teeth were dried with a gauze and assessed according to the CAST instrument (Table 1). The CPI probe was only used for removing plaque left behind after teeth cleaning. As they made the oral examination, the examiner's observation was recorded on a digital device and transcribed on an electronic file.

\section{3 $\mid$ Quality of life questionnaire}

The ECOHIS questionnaire is used for the evaluation of parents' perceptions regarding the oral health impact on the quality of life of pre-school children and their families. It comprises 13 items divided into two sections: the Child Impact Section (CIS) and Family Impact Section (FIS). The first section consists of 4 subdomains: symptoms (1 item), functions (4 items), psychology ( 2 items), and self-image/ social interaction (2 items). The FIS consists of two subdomains: parental distress (2 items) and family functions (2 items). The questionnaire is scored using a 5-point Likert scale, with alternatives ranging from 'never' to 'very often' (equivalent to scores of 0 and 4 , respectively) and including the alternative 'I don't know'. The total score ranges from 0 to 36 possible points for the CIS and 0 to 16 for the FIS; higher scores denote a higher negative impact on the quality of life of the individual and the family.

The present study used the validated Peruvian version of the ECOHIS questionnaire (P-ECOHIS). ${ }^{14}$ The questionnaire was delivered to the parents by placing it in the child's preschool control book. Two weeks later, the completed questionnaires were collected from the schoolteachers. Parents who had not returned the questionnaires received a reminder. After one month, a second reminder was sent. A second copy of the questionnaire was delivered to those parents who had not returned the questionnaire after three months. After one additional month, the collection period was considered closed.

\section{4 | Statistical analysis}

Data were analysed by an experienced statistician using the statistical package SPSS version 20.0 (IBM. Armonk NY, USA). Frequency distribution and descriptive results of P-ECOHIS by domain and study group were calculated. The CAST codes were clustered into two groups consisting of caries-free teeth (CAST 0, 1, 2, and 8) and of teeth affected by a carious lesion into dentine and its consequences in soft tissues (CAST 4 to 7). The P-ECOHIS scores between groups were compared using ANOVA. Post hoc analyses were conducted according to the method of Tamhane, which is suitable for different variances between groups. Tukey's method was used for the comparisons with equal variances. A MaxCAST code depicts the highest CAST code observed in a subject. CAST severity score is calculated according to a formula that gives weight to the codes progressively with the increase in code numbers. ${ }^{26}$ A significant difference was set at $\alpha=0.05$. 
TA B L E 2 Distribution of responses to P-ECOHIS by child and parent impact items among 3-year-olds $(n=213)$

\begin{tabular}{|c|c|c|c|c|c|c|}
\hline \multirow{2}{*}{$\begin{array}{l}\text { Impacts } \\
\text { Child impact } \\
\text { section }\end{array}$} & \multicolumn{2}{|c|}{$\begin{array}{l}\text { Never/Hardly } \\
\text { ever }\end{array}$} & \multicolumn{2}{|c|}{$\begin{array}{l}\text { Occasionally/ } \\
\text { Often/Very } \\
\text { Often }\end{array}$} & \multicolumn{2}{|c|}{ Don't know } \\
\hline & $\mathrm{N}$ & $\%$ & $\mathrm{~N}$ & $\%$ & $\mathrm{~N}$ & $\%$ \\
\hline \multicolumn{7}{|c|}{ Symptom domain } \\
\hline $\begin{array}{l}\text { Oral/dental } \\
\text { pain }\end{array}$ & 177 & 83.1 & 32 & 15.0 & 4 & 1.9 \\
\hline \multicolumn{7}{|c|}{ Functional domain } \\
\hline $\begin{array}{l}\text { Difficulty } \\
\text { drinking }\end{array}$ & 193 & 90.6 & 14 & 6.6 & 6 & 2.8 \\
\hline $\begin{array}{l}\text { Difficulty } \\
\text { eating }\end{array}$ & 191 & 89.7 & 11 & 5.2 & 11 & 5.2 \\
\hline $\begin{array}{l}\text { Difficulty } \\
\text { pronounc- } \\
\text { ing words }\end{array}$ & 139 & 65.3 & 65 & 30.5 & 9 & 4.2 \\
\hline $\begin{array}{l}\text { Missed pre- } \\
\text { school or } \\
\text { school }\end{array}$ & 208 & 97.7 & 4 & 1.9 & 1 & 0.5 \\
\hline
\end{tabular}

Psychological domain

$\begin{array}{ccccccc}\begin{array}{c}\text { Trouble } \\ \text { sleeping }\end{array} & 175 & 82.2 & 9 & 4.2 & 29 & 13.6 \\ \begin{array}{c}\text { Irritable or } \\ \text { frustrated }\end{array} & 174 & 81.7 & 0 & 0.0 & 39 & 18.3\end{array}$

Self-image/social interaction domain

$\begin{array}{lllllll}\begin{array}{l}\text { Avoided } \\ \text { smiling or }\end{array} & 192 & 90.1 & 6 & 2.8 & 15 & 7.0 \\ \text { laughing } & & & & & & \end{array}$

\begin{tabular}{|c|c|c|c|c|c|c|}
\hline $\begin{array}{l}\text { Avoided } \\
\text { talking }\end{array}$ & 194 & 91.1 & 0 & 0.0 & 19 & 8.9 \\
\hline $\begin{array}{l}\text { Family impact } \\
\text { section }\end{array}$ & $\mathrm{N}$ & $\%$ & $\mathrm{~N}$ & $\%$ & $\mathrm{~N}$ & $\%$ \\
\hline \multicolumn{7}{|c|}{ Parent distress domain } \\
\hline $\begin{array}{l}\text { Parents } \\
\text { been upset }\end{array}$ & 132 & 62.0 & 75 & 35.2 & 6 & 2.8 \\
\hline $\begin{array}{l}\text { Parents felt } \\
\text { guilty }\end{array}$ & 176 & 82.6 & 31 & 14.6 & 6 & 2.8 \\
\hline
\end{tabular}

Family function domain

$\begin{array}{lcccccc}\begin{array}{c}\text { Taken time } \\ \text { off from } \\ \text { work }\end{array} & 205 & 96.2 & 5 & 2.3 & 3 & 1.4 \\ \begin{array}{c}\text { Financial } \\ \text { impact }\end{array} & 177 & 83.1 & 34 & 16.0 & 2 & 0.9 \\ & & & & & & \end{array}$

Abbreviation: $\mathrm{N}$, number of responses.

\section{5 | Ethical considerations}

Ethical approval for this study was obtained from the Dental School of the San Martin de Porres University (USMP, Lima, Peru) institutional review board (Resolution $\mathrm{N}^{\circ}$
252-2013-D-FO-USMP). The study is registered at the Netherlands Trial Centre with number NTR 4510. All parents of the selected children received a letter with general information concerning the study and an informed consent form. They were requested to give permission for examining their child by signing the form. Once the examination process was completed, parents were invited to an education session about dental caries at which they were given a printed report of their child's oral health status. Those children who required urgent treatment were referred to the Dental School Clinic at USMP for appropriate care.

\section{3 | RESULTS}

\section{1 | Disposition of subjects}

Of the 308 children that were clinically examined, 213 parents returned the P-ECOHIS form (dropout percentage $=30.8$ ). The sample consisted of $46.5 \%$ girls and $53.5 \%$ boys. The mean age and standard deviation (SD) of the children were $3.04(0.15)$ years. The prevalence of dental caries (CAST codes 4-7) was $64.3 \%$. Including enamel carious lesions (CAST code 3), the prevalence was $93.4 \%$. The non-response analysis revealed a statistically significant difference in mean CAST severity score between the respondents (8.24) and the non-respondents (4.12).

\section{2 | Description of P-ECOHIS}

Table 2 displays the distribution of responses for the PECOHIS child and parent impact items. In the CIS, 'difficulty pronouncing words' (30.5\%) and 'oral/dental pain' (15\%) were the items most frequently reported in the category 'occasionally/often/very often'. 'Parents being upset' (35.2\%) and 'financial impact' (16\%) were the items most frequently reported in this category in the FIS.

The mean P-ECOHIS scores and standard deviation (SD) by district and sample are shown in Table 3. The sample mean P-ECOHIS score and SD were 1.77 (0.67). The highest sample mean P-ECOHIS scores in the child domain were obtained for 'child symptoms' (1.97) and 'child psychology' (2.02) while 'parent distress' scored highest in the parent domain.

\section{3 | Dental caries and quality of life}

Table 4 shows mean P-ECOHIS scores and 95\% Confidence Interval for the domains child and parent impact, and sample by MaxCAST codes 3, 5, and 6. Other MaxCAST codes were scored very infrequently and were therefore not included in the analysis. The mean P-ECOHIS scores for 'child symptoms', 'child functions', 'child impact', 'parent distress', and 'the sample' were statistically significantly higher for children 
TA B L E 3 Mean P-ECOHIS scores $(x)$ and standard deviation (SD) by groups and sample

\begin{tabular}{|c|c|c|c|c|c|c|c|c|c|c|c|c|}
\hline Domains & \multicolumn{3}{|l|}{ AG } & \multicolumn{3}{|c|}{ PG } & \multicolumn{3}{|c|}{ CG } & \multicolumn{3}{|c|}{ Sample } \\
\hline Child symptoms & 86 & 1.95 & 0.88 & 65 & 2.06 & 0.97 & 62 & 1.89 & 0.85 & 213 & 1.97 & 0.90 \\
\hline Child functions & 86 & 1.61 & 0.70 & 65 & 1.50 & 0.67 & 62 & 1.88 & 0.84 & 213 & 1.66 & 0.74 \\
\hline Child psychology & 86 & 1.92 & 1.41 & 65 & 1.87 & 1.41 & 62 & 2.33 & 1.60 & 213 & 2.02 & 1.48 \\
\hline $\begin{array}{l}\text { Child social } \\
\text { interactions }\end{array}$ & 86 & 1.70 & 1.26 & 65 & 1.40 & 1.04 & 62 & 2.04 & 1.46 & 213 & 1.71 & 1.28 \\
\hline Child impact & 86 & 1.74 & 0.71 & 65 & 1.62 & 0.64 & 62 & 2.02 & 0.81 & 213 & 1.78 & 0.74 \\
\hline Parent's distress & 86 & 1.81 & 0.91 & 65 & 1.65 & 0.89 & 62 & 2.42 & 0.83 & 213 & 1.94 & 0.93 \\
\hline Family functions & 86 & 1.55 & 0.79 & 65 & 1.33 & 0.50 & 62 & 1.73 & 0.80 & 213 & 1.54 & 0.73 \\
\hline Family impact & 86 & 1.68 & 0.81 & 65 & 1.49 & 0.59 & 62 & 2.08 & 0.75 & 213 & 1.74 & 0.76 \\
\hline
\end{tabular}

Abbreviations: AG, active intervention group; CG, control group; PG, passive intervention group.

with MaxCAST codes 5 and 6 than for those with MaxCAST code 3 . Three-year-olds having a dentine cavity with or without pulp involvement as the most severe caries condition have a poorer quality of life than their peers with a carious lesion in enamel as the most severe caries condition $(P<.05)$.

The mean P-ECOHIS scores and standard errors, and mean difference in P-ECOHIS scores between 3-year-olds with MaxCAST codes 0-3, 8, and with MaxCAST codes 4-7 are presented in Table 5. The mean P-ECOHIS score was statistically significantly lower for children with MaxCAST codes 0-3, 8 (caries-free) than for children with MaxCAST codes 4-7 (cavitated dentine carious lesion with or without pulp involvement) for all P-ECOHIS domains and the sample except for 'child symptoms' and 'child psychology'.

\section{4 | DISCUSSION}

\section{1 | Research methodology}

The present study represents a baseline for a 3-year-long intervention study aimed at reducing the prevalence of dental caries among 3-year-olds. ${ }^{23}$ Hence, the three intervention groups are included in the analyses. The study was carried out in low-SES areas. People of low SES hold different priorities in life from those of medium and high SES. The latter groups tend to have a greater understanding of the reason for and impact of research and may, therefore, show a higher level of cooperation. Although the dropout percentage in the present study was substantial (31\%), taking into account the SES of the study group this percentage may have to be considered as acceptable. Similar results were reported in low-SES children's groups in Brazil, with dropout percentages of $29^{27}$ and $26^{28}$ for self-reported questionnaires.
In contrast to a structured interview, which usually results in a low dropout percentage, the questionnaire for the present study was sent to the children's homes. This method holds a certain risk as respondents may not return the questionnaire. We used all means at our disposal to increase the number of returned questionnaires. We stopped the retrieval process only after sending out four reminders and having waited four months. The non-response analysis showed that the children from whom the questionnaires were not returned had a significantly lower caries severity score than the children who had returned the questionnaires. Could it be that the non-response parents had not experienced much distress regarding oral health problems with their children, and thought it not necessary to fill in the questionnaire? Answering this question would have required interviewing parents face-to-face but this method is demanding and costly.

A recent systematic review of OHRQoL instruments for children and adolescents emphasised that ECOHIS is the most complete instrument for measuring OHRQoL in preschool children and their families. The instrument is considered reliable, with good responsiveness and interpretability, and has been translated into and culturally adapted to fit more than 15 languages. ${ }^{29}$

\section{5 | MAIN FINDINGS}

\section{1 | OHRQoL}

The present study showed that 'difficulty pronouncing words' (30.5\%) and 'oral/dental pain' (15\%) bothered the children most. These outcomes differ from those reported in the first study to use the P-ECOHIS questionnaire in Peruvian children, where 'pain' $(54.9 \%)$ and 'eating problems' (49.7\%) were most frequently reported. ${ }^{14}$ The difference in 'pain perception' may be due to the age group (3- to 


\begin{tabular}{|c|c|c|c|c|c|c|}
\hline \multirow[b]{2}{*}{ ECOHIS domains } & \multirow[b]{2}{*}{ MaxCAST Code } & \multirow[b]{2}{*}{$\mathbf{N}$} & \multirow[b]{2}{*}{$(x)$} & \multicolumn{2}{|c|}{ CI 95\% } & \multirow[b]{2}{*}{$P$ value } \\
\hline & & & & Lower & Upper & \\
\hline \multirow[t]{4}{*}{ Child symptoms } & 3 & 62 & $1.79^{\mathrm{a}}$ & 1.53 & 2.05 & \multirow[t]{4}{*}{.034} \\
\hline & 5 & 78 & $1.91^{\mathrm{a}, \mathrm{b}}$ & 1.73 & 2.09 & \\
\hline & 6 & 42 & $2.29^{\mathrm{b}}$ & 1.99 & 2.58 & \\
\hline & Total & 182 & 1.96 & 1.82 & 2.09 & \\
\hline \multirow[t]{4}{*}{ Child functions } & 3 & 62 & $1.44^{\mathrm{a}}$ & 1.29 & 1.60 & \multirow[t]{4}{*}{.009} \\
\hline & 5 & 78 & $1.82^{\mathrm{b}}$ & 1.62 & 2.02 & \\
\hline & 6 & 42 & $1.71^{\mathrm{a}, \mathrm{b}}$ & 1.52 & 1.89 & \\
\hline & Total & 182 & 1.67 & 1.56 & 1.78 & \\
\hline \multirow[t]{4}{*}{ Child psychology } & 3 & 62 & 1.77 & 1.40 & 2.13 & \multirow[t]{4}{*}{.159} \\
\hline & 5 & 78 & 2.02 & 1.67 & 2.37 & \\
\hline & 6 & 42 & 2.33 & 1.87 & 2.80 & \\
\hline & Total & 182 & 2.01 & 1.79 & 2.22 & \\
\hline \multirow{4}{*}{$\begin{array}{l}\text { Child social } \\
\text { interactions }\end{array}$} & 3 & 62 & 1.42 & 1.18 & 1.66 & \multirow[t]{4}{*}{.079} \\
\hline & 5 & 78 & 1.76 & 1.47 & 2.05 & \\
\hline & 6 & 42 & 1.90 & 1.44 & 2.37 & \\
\hline & Total & 182 & 1.68 & 1.49 & 1.86 & \\
\hline \multirow[t]{4}{*}{ Child impact } & 3 & 62 & $1.55^{\mathrm{a}}$ & 1.39 & 1.70 & \multirow[t]{4}{*}{.004} \\
\hline & 5 & 78 & $1.86^{\mathrm{b}}$ & 1.68 & 2.04 & \\
\hline & 6 & 42 & $1.96^{\mathrm{b}}$ & 1.74 & 2.17 & \\
\hline & Total & 182 & 1.78 & 1.67 & 1.88 & \\
\hline \multirow[t]{4}{*}{ Parent's distress } & 3 & 62 & $1.60^{\mathrm{a}}$ & 1.42 & 1.79 & \multirow[t]{4}{*}{.001} \\
\hline & 5 & 78 & $1.99^{\mathrm{b}}$ & 1.78 & 2.21 & \\
\hline & 6 & 42 & $2.24^{\mathrm{b}}$ & 1.91 & 2.57 & \\
\hline & Total & 182 & 1.92 & 1.78 & 2.06 & \\
\hline \multirow[t]{4}{*}{ Family functions } & 3 & 62 & 1.37 & 1.21 & 1.53 & \multirow[t]{4}{*}{.078} \\
\hline & 5 & 78 & 1.65 & 1.45 & 1.85 & \\
\hline & 6 & 42 & 1.57 & 1.38 & 1.76 & \\
\hline & Total & 182 & 1.54 & 1.42 & 1.65 & \\
\hline \multirow[t]{4}{*}{ Family impact } & 3 & 62 & $1.49^{\mathrm{a}}$ & 1.33 & 1.65 & \multirow[t]{4}{*}{.003} \\
\hline & 5 & 78 & $1.82^{\mathrm{b}}$ & 1.62 & 2.02 & \\
\hline & 6 & 42 & $1.90^{\mathrm{b}}$ & 1.69 & 2.12 & \\
\hline & Total & 182 & 1.73 & 1.61 & 1.84 & \\
\hline \multirow[t]{4}{*}{ Sample } & 3 & 62 & $1.53^{\mathrm{a}}$ & 1.39 & 1.67 & \multirow[t]{4}{*}{.001} \\
\hline & 5 & 78 & $1.85^{\mathrm{b}}$ & 1.68 & 2.02 & \\
\hline & 6 & 42 & $1.94^{\mathrm{b}}$ & 1.75 & 2.13 & \\
\hline & Total & 182 & 1.76 & 1.66 & 1.86 & \\
\hline
\end{tabular}

T A B L E 4 Mean P-ECOHIS scores (X) and 95\% Confidence Interval (CI) for ECOHIS domains and impact by MaxCAST codes $3,5,6$

Note: Tamhane test statistical difference.

${ }^{\mathrm{ab}}$ Statistical difference $P<.05$.

5-year-olds) of the first report, which was slightly higher than that of the present study. Dental caries is an age-related disease and will have developed and progressed in more teeth of older than younger children, particularly high-caries-risk children of low SES as investigated in the two study groups. ${ }^{30}$ Evidently, toothache leads to eating problems and that may explain the high percentage of the 'eating problems' category in the Lopez-Ramos et $a l^{14}$ study. In the same way, the higher percentage of 'difficulty pronouncing words' in the current study may be a linguistic development issue relevant to the age of the children of this study. In both OHRQoL studies, 'being upset' was the most reported family impact factor, slightly higher in the first OHRQoL study (48.4\%) than in the present one 
T A B L E 5 Mean P-ECOHIS scores ( $x$ ), standard error (SE) and mean difference in P-ECOHIS scores between 3-year-olds with MaxCAST codes 0-3, 8 and with MaxCAST codes 4-7

\begin{tabular}{|c|c|c|c|c|c|c|c|c|}
\hline Domains & \multicolumn{3}{|c|}{ CAST 0-3, 8} & \multicolumn{3}{|c|}{ CAST 4 to 7} & Mean difference & P value \\
\hline Child symptoms & 76 & 1.83 & 0.11 & 137 & 2.04 & 0.07 & -0.21 & .094 \\
\hline Child functions & 76 & 1.45 & 0.07 & 137 & 1.77 & 0.07 & -0.33 & .002 \\
\hline Child psychology & 76 & 1.77 & 0.16 & 137 & 2.16 & 0.13 & -0.39 & .062 \\
\hline Parent's distress & 76 & 1.65 & 0.09 & 137 & 2.09 & 0.08 & -0.44 & .001 \\
\hline Family functions & 76 & 1.39 & 0.07 & 137 & 1.62 & 0.07 & -0.22 & .034 \\
\hline Family impact & 76 & 1.52 & 0.07 & 137 & 1.86 & 0.07 & -0.33 & .002 \\
\hline Sample & 76 & 1.54 & 0.06 & 137 & 1.90 & 0.06 & -0.35 & $<.001$ \\
\hline
\end{tabular}

(35.2\%). It shows that parents are concerned with the dental caries on their children.

'Oral/dental pain' and 'difficulty pronouncing words' have been the most frequently reported items for the CIS among 3- to 5-year-olds in studies across several countries and continents. These studies have shown a variation in frequency scores that has depended on the severity of dental caries among the study population, with Argentina at $29.1 \%^{31}$; Australia at $38.5 \%{ }^{32}$; Brazil from $4.6 \%{ }^{16}$ to $79.7 \%^{33}$; China at $39.4 \%^{34}$; the United States at $51 \%^{35}$; Trinidad at $10 \%^{36}$; and Uganda at $36.5 \% .^{37}$

For the FIS, the results of the present study showed that the most frequently reported item was 'being upset' (35.2\%), which is in line with the previous report from Peru. ${ }^{14}$ Worldwide the outcomes of a variety of studies are in accordance with the outcome of the present study in terms of the FIS ${ }^{16,31,34}$ but others have reported 'feeling guilty ${ }^{32,36}$ as the most frequently reported item. The questionnaires in the present study were entirely responded to by mothers. Where fathers were the proxy, a lower perception of the negative impact of dental caries on their children's quality of life occurred. ${ }^{16}$ Caregivers have limited abilities to recognise dental caries unless it presents evident cavities or symptoms. ${ }^{38}$ This means that the family member who spends more time with their offspring, most often the mother, might have the greatest understanding of their feelings.

\section{2 | Dental caries status and OHRQoL}

The present study is the first one in Peru to have investigated the relationship between dental caries, using the CAST instrument, and the quality of life of children aged 3 years. Previously, this relationship was studied in children under 6 years of life ${ }^{20}$ and pre-school children of a similar populations from Lima, ${ }^{21}$ also in Peruvian adolescents who were 11- to 12 years old ${ }^{39}$ and 11 - to 14 years old. ${ }^{40}$ Studies using ECOHIS showed distinctive results with previous Peruvian reports for the Child Impact Section (CIS) but coincide with the Family Impact Section (FIS). ${ }^{14,21,22}$ Lopez-Ramos et al (2013), reported that parents from 3-to-5-year-old children reported 'pain' (54.9\%), 'difficulties in eating' (49.7\%) and 'drinking' (41.9\%) most frequently on the CIS and 'being upset' $(47.1 \%)$ on the FIS. ${ }^{14}$ Parents taking their children (under 6 years of age) to the dental unit of the Peruvian Children Hospital reported 'self-image/social interaction' more frequently for the CIS and 'being upset' for the FIS, the authors argued that younger mothers were more aware of their children health status (more sensitive to their children distress), ${ }^{21}$ something that other authors have claimed. ${ }^{14,38}$ Recently, it has been stated that 'functional limitations' and 'social aspects' were the most reported for the CIS and 'being upset' the most reported item for the FIS, in a highcaries prevalence population of children from 3-to-5-years in suburban Lima. ${ }^{22}$ Parents' reactions to their children discomfort concur with previous publications from Peru, but their interpretation of their children symptoms might be related to caries prevalence or the severity of the lesions. This study reported a very high prevalence of dental caries $(93.4 \%)$ as it was also for the study of northern Lima $(98.8 \%) .{ }^{22}$ Lower but still concerning proportions were presented by the Peruvian Children Hospital $(52.6 \%)^{21}$ and the report by Lopez-Ramos et al (2013) (76.5\%). ${ }^{14}$ The high prevalence of the disease and consequences on their quality of life means that the present oral health promotion or prevention strategies are not effective on these Peruvian age groups.

Usually, the DMF index is used for determining a possible association between dental caries and the ECOHIS domains. However, the DMF index has limitations as the $\mathrm{d}$ component does not distinguish between cavitated dentine carious lesions that have or have not reached the pulp chamber. This may impact on the study result as a pulpally infected tooth causes more distress than a cavitated tooth that can be restored. ${ }^{27}$ Among the caries assessment instruments currently in use, only the CAST instrument has a code for a pulpally involved carious tooth and also for an abscessed tooth. ${ }^{41}$ In the present study, 
which is the first study to use CAST to investigate a relationship between dental caries and the OHRQoL of subjects, a substantial number of children had at least one tooth with pulpal infection. However, this finding did not result in children with this condition having a worse OHRQoL than their peers who had restorable dental cavities. A significant difference in OHRQoL was observed only between children who had an enamel carious lesion as the highest CAST code and children who had a dentine cavity (codes 5 and 6) as the highest score, the latter having a worse OHRQoL. A worse OHRQoL was also observed in children with a cavitated dentine carious lesion in comparison with children who had no cavities.

The present study showed a significant relationship between 'parent distress' and the presence of tooth cavities but not with 'family functions'. The impact of dental caries is generally perceived only when the disease process has destroyed dental structure and clinical signs are evident, such as cavitation on primary teeth or the presentation of pain. ${ }^{42}$ In Peru, on average, parents bring their children to the dental office for the first time when they reach the age of 4 , by which time many carious lesions have reached the dentine and have become sensitive. ${ }^{43}$ Parents visit the dental office this late as they consider primary teeth not to be as important as permanent ones. With this in mind, the findings of the present study suggest that a dental caries prevention programme should be implemented to integrate oral health into general health policies at $\mathrm{MCH}$ clinics, from birth, in order to keep healthy teeth healthy for life.

In conclusion, the presence of teeth with cavitated dentine carious lesions with and without pulpal involvement impacts negatively on the OHRQoL of 3-year-old children from low-SES districts from Lima, Peru. The CAST instrument appears to be a suitable caries assessment for epidemiological studies.

\section{ACKNOWLEDGMENTS}

We would like to express our deepest appreciation to Diana Zelada and Julia Diaz (Paediatric Dentistry Professors of the San Martin de Porres University) for their invaluable work during the epidemiological study. Our gratitude goes to all the pre-school directors and teachers who supported the research team in performing the oral examination in the children and especially to all the participants. We thank statistician Dr EM Bronkhorst for analysing the data and interpretation of outcomes. Our special thanks go to Mrs S. van Tonder for editing the English grammar and syntax. This research was funded by the World Dental Federation (FDI) and supported by the Department of Global Oral Health of the Radboud University Medical Centre, Nijmegen, The Netherlands, and the Department of Paediatric Dentistry of the San Martin de Porres University, Dental School, Lima, Peru.

\section{CONFLICT OF INTEREST}

The authors declare that no competing interests exist.

\section{AUTHORS' CONTRIBUTIONS}

EP contributed to data collection and interpretation of data and drafted the manuscript; RSV contributed to the conception of the study and interpretation of data and drafted the manuscript; JEF contributed to the conception of the study and interpretation of data and drafted the manuscript. All authors gave final approval and agree to be accountable for all aspects of the work.

\section{CONSENT}

All authors declare that written informed consent was obtained from the mothers of all the children who participated in the present study.

\section{ORCID}

Eraldo Pesaressi (D) https://orcid.org/0000-0003-0806-1011

\section{REFERENCES}

1. Locker D. Family impact of child oral and oro-facial conditions. Community Dent Oral Epidemiol. 2002;30:438-448.

2. Villena-Sarmiento R, Pachas-Barrionuevo F, Sanchez-Huaman Y, Carrasco-Loyola M. Early childhood caries on children under 6 years of age from sub-urban areas of Lima. Rev Estomatol Herediana. 2011;21:79-86.

3. Filstrup SL. Early childhood caries and quality of life: child and parents' perspectives. Pediatr Dent. 2005;25:431-440.

4. Piovesan C, Batista A, Vargas-Ferreira F, Machado-Ardenhi T. Oral health-related quality of life in children: Conceptual Issues. Rev Odont Cienc. 2009;24:81-85.

5. John MT, Hujoel P, Miglioretti DL, LeResche L, Koepsell TD, Micheelis W. Dimensions of oral-health- related quality of life. $J$ Dent Res. 2004;83:956-960.

6. Jokovic A, Locker D, Stephens M, Kenny D, Thompson B, Guyatt G. Validity and reliability of a questionnaire for measuring child oral-health related quality of life. J Dent Res. 2002;81: 459-463.

7. Broder HL, McGrath C, Cisneros GJ. Questionnaire development: face validity and item impact testing of the Child Oral Health Impact Profile. Community Dent Oral Epidemiol. 2007;35:8-19.

8. Guerunpong S, Tsakos G, Sheiham A. Developing and evaluating oral health-related quality of life index for children: The CHILD OIDP. Community Dent Health. 2004;21:161-169.

9. Pahel BT, Rozier RG, Slade GD. Parental perceptions of children's oral health: The Early Childhood Oral Health Impact Scale (ECOHIS). Health Qual Life Outcomes. 2007;5:6.

10. Tesch FC, DeOliveira BH, Leao A. Measuring the impact of oral health problems on children's quality of life: conceptual and methodological issues. Cad saude publica. 2007;23:2555-2564. 
11. Jokovic A, Locker D, Tompson B, Guyatt G. Questionnaire for measuring oral health-related quality of life in eight-to ten-year-old children. Pediatr Dent. 2004;26:512-518.

12. Rebok G, Riley A, Forrest C, et al. Elementary school-aged children's reports of their health: a cognitive interviewing study. Qual Life Res. 2001;10:59-70.

13. Bordoni N, Ciaravino O, Zambrano O, Villena R, Beltran-Aguilar E, Squassi A. Early childhood oral health impact scale (ECOHIS): translation and validation in Spanish language. Acta Odontol Latinoam. 2012;25:270-278.

14. Lopez Ramos RP, García Rupaya CR, Villena-Sarmiento R, Bordoni NE. Cross cultural adaptation and validation of the Early Childhood Health Impact Scale (ECOHIS) in Peruvian preschoolers. Acta Odontol Latinoam. 2013;26:60-67.

15. Clementino MA, Gomes MC, Pinto-Sarmento TC, Martins CC, Granville-Garcia AF, Paiva SM. Perceived impact of dental pain on the quality of life of preschool children and their families. PLoS ONE. 2015;19:10.

16. Correa-Faria P, Daher A, Matias Freire M, de Abreu M, Bönecker M, Costa LR. Impact of untreated dental caries severity on the quality of life of preschool children and their families: a cross-sectional study. Quality of Life Res. 2018;27(12):3191-3198. https:// doi.org/10.1007/s11136-018-1966-5.

17. Ramos-Jorge J, Pordeus IA, Ramos-Jorge ML, Marques LS, Paiva SM. Impact of untreated dental caries on quality of life of preschool children: different stages and activity. Community Dent Oral Epidemiol. 2014;42:311-322.

18. WHO. Oral Health Surveys: Basic Methods. 2013; 5th ed.

19. Ismail AI, Sohn W, Tellez M, et al. The International Caries Detection and Assessment System (ICDAS): an integrated system for measuring dental caries. Community Dent Oral Epidemiol. 2007;35:170-178.

20. Frencken JE, de Amorim RG, Faber J, Leal SC. The caries assessment spectrum and treatment (CAST) index: rational and development. Int Dent J. 2011;61:117-123.

21. Torres-Ramos G, Blanco-Victorio DJ, Chavez-Sevillano MG, Apaza-Ramos S, Antezana-Vargas V. Impact of early childhood caries in oral health-related quality of life in peruvian children below 71 months of age. Odontol Sanmarquina. 2015;18(2):87-94.

22. Morales-Miranda L, Gonzales WG. Dental caries and its clinical consequences related to the impact on the quality of life of preschoolers of a state school. Rev Estomatol Herediana. 2019;29(1):17-29.

23. Pesaressi E, Villena RS, van der Sanden W, Frencken JE. Impact of health centre nurses on the reduction of early childhood caries in Lima, Peru. Br J Med Med Res. 2015;5:1169-1176.

24. INEI: Peruvian National Institute of Statistics and Informatics. [cited 2018 April] Available from: http://iinei.inei.gob.pe/microdatos/.

25. Pesaressi E, Villena RS, Bronkhorst EM, Frencken JE.Dental caries in three-year-old preschool children in Lima, Peru assessed according to the CAST instrument. Accepted for publication in JADA.

26. Ribeiro A, Maciel IP, de Souza Hilgert AL, Bronkhorst EM, Frencken JE, Leal SC. Caries assessment spectrum treatment: the severity score. Int Dent J. 2018;68:84-90.

27. Leal SC, Bronkhorst EM, Frencken JE. Untreated cavitated dentine lesions: impact on children's quality of life. Caries Res. 2012;46:102-106.

28. Antunez LA, Ornellas G, Fraga RS, Atunes LS. Oral health outcomes: the association of clinical and socio-dental indicators to evaluate dental caries in preschool children. Cien Saude Colet. 2018;23:491-500.

29. Zaror C, Pardo Y, Espinoza-Espinoza G, et al. Assessing oral healthrelated quality of life in children and adolescents: a systematic review and standardized comparison of available instruments. Clin Oral Invest. 2018;. https://doi.org/10.1007/s00784-018-2406-1.

30. Corrêa-Faria P, Paixão-Gonçalves S, Paiva SM, Pordeus IA. Incidence of dental caries in primary dentition and risk factors: a longitudinal study. Braz Oral Res. 2016;30(1):e59.

31. Fernandez CN, Cambria S, Vuoto ER, et al. Early childhood caries, demand for dental care and parental perception of oral health in social risk pre-schoolers from Mendoza - Argentina. Fac Odont UNCиуо. 2010;4:29-37.

32. Arrow P, Klobas E. Evaluation of the Early Childhood Oral Health Impact Scale in an Australian preschool child population. Aus Dent J. 2015;60:375-381.

33. Firmino RT, Gomes MC, Clementino MA, Martins CC, Paiva SM, Granville-Garcia AF. Impact of oral health problems on the quality of life of preschool children: a case-control study. Int J Paediatr Dent. 2016;26:242-249.

34. Wong HM, McGrath C, King N, Lo E. Oral Health-Related Quality of Life in Hong Kong Preschool Children. Caries Res. 2011;45:370-376.

35. Born CD, Divaris K, Zeldin LP, Rozier RG. Influences on preschool children's oral health-related quality of life as reported by English and Spanish-speaking parents and caregivers. J Pub Health Dent. 2016;. https://doi.org/10.1111/jphd,12152.

36. Naidu R, Nunn J, Donnelly-Swift E. Oral health-related quality of life and early childhood caries among preschool children in Trinidad. BMC Oral Health. 2016;16:128.

37. Masumo R, Bardsen A, Mashoto K, Åstrøm AN. Child- and family impacts of infants' oral conditions in Tanzania and Uganda- a cross-sectional study. BMC Oral Health. 2012;5:538.

38. Fernandes IB, Pereira TS, Souza DS, Ramos-Jorge J, Marques LS, Ramos-Jorge ML. Severity of dental caries and quality of life for toddlers and their families. Pediatric Dent. 2017;39:118-123.

39. Bernabé E, Sheiham A, Tsakos G. A comprehensive evaluation of the validity of Child-OIDP: further evidence from Peru. Community Dent Oral Epidemiol. 2008;36:317-325.

40. Pulache J, Abanto J, Oliveira LB, Bönecker M, Porras JC. Exploring the association between oral health problems and oral health-related quality of life in Peruvian 11- to 14-year-old children. Int J Paediatr Dent. 2016;26(2):81-90.

41. Castro A, Vianna M, Mendes C Comparison of caries lesion detection methods in epidemiological surveys: CAST, ICDAS and DMF. BMC Oral Health. 2018;18:122.

42. Chaffee BW, Rodrigues PH, Kramer PF, Vitolo MR, Feldens CA. Oral health-related quality-of-life scores differ by socioeconomic status and caries experience. Community Dent Health. 2017;4:216-224.

43. Pachas-Barrionuevo F, Sanchez-Huaman Y, Carrasco-Loyola M, Villena-Sarmiento R. Profile of health care in pregnant women and children from 0-71 months of age, from a Health Centre of the North Cone -Carabayllo, Lima-Peru. Rev Estomatol Herediana. 2008;18:83-92.

How to cite this article: Pesaressi E, Villena RS, Frencken JE. Dental caries and oral health-related quality of life of 3-year-olds living in Lima, Peru. Int J Paediatr Dent. 2020;30:57-65. https://doi.org/10.1111/ ipd.12582 